\title{
KAJIAN POTENSI HUTAN MANGROVE DI LAMPUNG MANGROVE CENTER (LMC) UNTUK PENGEMBANGAN EKOWISATA BERBASIS MASYARAKAT
}

\author{
${ }^{1}$ Rusita, ${ }^{2}$ Elly L. ${ }^{3}$ Rustiati, ${ }^{4}$ Gunardi Djoko Winarno, ${ }^{5}$ Bainah Sari Dewi, ${ }^{6}$ Cahyaning Windarni \\ Jurusan Kehutanan Fakultas Pertanian Universitas Lampung \\ Jurusan Biologi Fakultas Matematika dan Ilmu Pengetahuan Alam Universitas Lampung \\ Jl. Sumatri Brojonegoro No 1 Bandar lampung, 35145 \\ Korespondensi Email : rusitaunila@gmail.com
}

Diterima : 10 September 2016 Disetujui : 20 November 2016

\begin{abstract}
Intisari
Hutan menyediakan pelayanan ekosistem yang mendasar bagi penghidupan dan kesejahteraan penduduk di sekitar hutan, khususnya mereka yang miskin. Salah satu upaya pemerintah untuk meningkatkan kesejahteraan masyarakat yang tinggal di sekitar hutan adalah melalui ekowisata yang memberikan keterlibatan penuh kepada masyarakat sekitar mulai dari perencanaan, pengelolaan hingga evaluasi. Salah satu kawasan yang potensial untuk dikembangkan sebagai kawasan ekowisata berbasis masyarakat adalah Lampung Mangrove Center (LMC) yang terletak di Desa Margasari Kabupaten Lampung Timur dengan luasan 700 ha. Penelitian bertujuan untuk mengkaji potensi hutan mangrove sebagai tujuan ekowisata berbasis masyarakat. Data dikumpulkan melalui pengamatan langsung terhadap potensi hutan mangrove, wawancara dengan wisatawan, masyarakat serta instansi terkait dan menghitung daya dukung. Data yang telah dikumpulkan dianalisis secara kualitatif menggunakan SWOT dengan harapan agar diperoleh gambaran potensi hutan mangrove untuk pengembangan ekowisata berbasisi masyarakat. Potensi hutan mangrove di LMC masuk dalam kategori sedang. Sebanyak $98 \%$ persepsi masyarakat menyatakan setuju jika dikembangkan sebagai ekowisata berbasis masyarakat. Motivasi wisatawan yang berkunjung sebanyak $27 \%$ untuk penelitian, $37 \%$ untuk rekreasi dan sisanya menyusuri mangrove menggunakan sampan (36\%). Daya dukung riil kawasan LMC dapat menampung sebanyak 170 orang/hari, sedangkan daya dukung fasilitas dan amenitas 174 orang / kunjungan. Analisis SWOT menggambarkan hutan mangrove di LMC berpotensi untuk dikembangkan sebagai tujuan ekowisata berbasis masyarakat.
\end{abstract}

Kata Kunci: Ekowisata Berbasis Masyarakat, Hutan Mangrove, Lampung Mangrove Center

\begin{abstract}
Forest provides basic ecosystem services to adjacent local people welfare. Ecotourism is one of the goverment program to improve the livelihood, by full local people involvement on planning, management and evaluation. Margasari, East L ampung, with its 700 ha mangrove forest, has a ahigh potential natural resources to develop community based ecotourism program. Study on evaluating mangrove forestas community based ecotourism was conducted in Lampung Mangrove Center, Margasari, East Lampung. collected data were analyzed qualitatively using SWOT with hope to obtain a mangrove forest potential for community-based ecotourism development. Potential of mangrove forests in LMC into category medium. Total of $98 \%$ agreed if the community perception was developed as a community-based ecotourism. Motivation tourists visiting as much as $27 \%$ for research, $37 \%$ for recreation and rest along the mangroves by boat (36\%). LMC real carrying capacity of area can accommodate as many as 170 people / day, while the carrying capacity of the facility and amenitas 174 people / visit. SWOT analysis illustrates the mangrove forests in LMC has potential to be developed as a community-based ecotourism destination.
\end{abstract}

Keywords: Community based ecotourism, Lampung Mangrove Center, Mangrove

DOI:10.30598/jhppk.2016.1.2.84

ISSN ONLINE : 2621-8798 


\section{PENDAHULUAN}

Indonesia adalah salah satu dari 70 negara yang sepakat menjadikan pengentasan kemiskinan sebagai prioritas kebijakan utama melalui strategi penanggulangan kemiskinan. Di banyak negara, termasuk Indonesia, ciri khusus kemiskinan di kawasan hutan dan peran potensial hutan bagi pengentasan kemiskinan masih kurang diperhatikan. Masyarakat yang tinggal di sekitar hutan merupakan salah satu kelompok miskin terbesar di Indonesia. Sekitar 48,8 juta orang tinggal pada lahan hutan negara dan sekitar 10,2 juta di antaranya dianggap miskin (Wirendo, S. 2009).

Masyarakat yang tinggal di hutan cenderung miskin secara menahun, karena tidak adanya prasarana, sulitnya komunikasi dan jauhnya jarak hutan dari pasar, sarana kesehatan dan pendidikan sangat membatasi pilihan sumber penghidupan. Akibatnya, sulit bagi masyarakat miskin di hutan untuk keluar dari kemiskinan. Disisi lain, biaya penyediaan pelayanan pemerintah bagi daerah daerah terpencil sangat tinggi. Salah satu upaya pemerintah untuk meningkatkan kesejahteraan masyarakat di sekitar hutan yakni melalui kegiatan perencanaan, pelaksanaan, pengelolaan, usaha ekowisata hingga evaluasi sehingga peran masyarakat lebih maksimal.

Salah satu daerah yang potensial untuk dikembangkan sebagai kawasan ekowisata berbasis masyarakat adalah Desa Margasari Kabupaten Lampung Timur yang memiliki areal hutan mangrove sekitar700ha(Kustanti,2007).Sebelumdikembangkan sebagai destinasi tujuan wisata, perlu dikaji terlebih dahulu manfaat langsung hutan mangrove sehingga masyarakat akan terbuka wawasan pengetahuannya dalam mengelola mangrove untuk tujuan ekowisata. Berbagai aspek biodiversitas dan budaya masyarakat akan diteliti sehingga menjadi sumber manfaat yang dapat dijual untuk para wisatawan.

Hutan mangrove Desa Margasari menjadi pusat pengelolaan hutan di Lampung lestari, upaya mengantisipasi adalah bagaimana memberikan persepsi yang tepat kepada masyarakat tentang biodiversity hutan mangrove untuk kegiatan ekowisata serta bagaimana masyarakat dapat menjadi peran utama dalam implementasi ekowisata di hutan mangrove. Masalah yang dihadapi adalah bagaimana ekowisata berbasis masyarakat dapat terwujud dan menjadikan hutan mangrove sebagai sumber penghasilan tanpa harus menebang dan merusak, tujuan penelitian yakni mengkaji potensi hutan mangrove di Lampung Mangrove Center untuk dikembangkan sebagai ekowisata berbasis masyarakat.

\section{METODE PENELITIAN}

Penelitian dilaksanakan pada Bulan September 2015 di Lampung Mangrove Center (LMC) Desa Margasari Kecamatan Labuhan Maringgai Kabupaten Lampung Timur. Bahan penelitian yang diperlukan yakni buku referensi, daftar pertanyaan (kuisioner), peta kawasan. Alat-alat yang digunakan yakni kamera untuk dokumentasi dan komputer. Pengambilan data menggunakan data primer dan sekunder.

\section{Identifikasi Potensi LMC}

Kualitas atraksi alam dicermati dari sudut pandang otensitas (keaslian), keunikan, keindahan, keutuhan, ketersediaan lahan pengembangan, aksesibilitas, amenitas, dan kelembagaan.

\section{Data Persepsi dan Preferensi Masyarakat dan Wisatawan}

Persepsi masyarakat diketahui melalui data kondisi sosial ekonomi masyarakat, dan data persepsi terhadap hutan mangrove untuk pengembangan ekowisata berbasis masyarakat yang melalui wawancara,dengan metode Purposive sampling. Data persepsi wisatawan mencakup tujuan wisatawan, luas areal untuk berwisata, dan data persepsi terhadap hutan mangrove. Wawancara dilakukan menggunakan metode Accidental sampling, yaitu pengambilan responden dengan cara siapa saja yang kebetulan ditemukan dilokasi penelitian.

\section{Daya Dukung}

Variabel daya dukung kawasan meliputi daya dukung fisik, daya dukung riil, dan daya dukung ekologis. Adapun rumus daya dukung ekologi sebagai berikut: 
Analisis daya dukung ekologis (Fandeli, 2002)

$$
\operatorname{AR} \frac{D \times a}{C d \times T F \times 43,560} .
$$

Keterangan :

AR : Area yang dibutuhkan untuk kegiatan wisata

D : Permintaan wisatawan untuk suatu aktifitas

a : Kebutuhan area setiap wisatawan dalam feet

Cd : Jumlah hari dalam satu tahun yang dapat dipergunakan untuk suatu kegiatan tertentu

TF : Faktor pemulihan nilai TF 1,5 untuk berenang; 2,0 untuk berperahu; 1,5 untuk piknik; dan 1,0 untuk berkemah.

43.560 : Konstanta (diperoleh dari konversi acre ke feet $^{2}$ )

Analisis daya dukung fisik (PCC: Physical CarryingCapacity) (Cifuentes dalam Wiratmo (Fandeli, 2002):

$$
\mathrm{PCC}=\mathrm{A} x \underset{\mathrm{B}}{\frac{1}{1}} \mathrm{xf} .
$$

Keterangan :

PCC : Jumlah maksimum pengunjung yang secara fisik tercukupi oleh ruang yang disediakan pada waktu tertentu;

A : Luas area yang digunakan untuk wisata

B : Luas area yang dibutuhkan oleh seseorang wisatawan untuk berwisata dengan tetap memperoleh kepuasan

Rf : Faktor rotasi (jumlah kunjungan per hari)set

Analisis daya dukung riil $(\mathrm{RCC}=\mathrm{Real}$ Carrying Capacity)

$$
\begin{aligned}
& \mathrm{RCC}=\operatorname{POCC} \times \frac{100-C f 1}{100} \mathbf{x} \frac{100-C f 2}{100} \times \mathbf{x} \ldots . . \frac{100-C f n}{100} \\
& \mathrm{Cf}=\frac{M t 1}{M t 2} \times 100
\end{aligned}
$$

Keterangan :

Mt $1=$ Batas besaran variabel

Mt $2=$ Batas variabel total
Faktor koreksi (CF) adalah faktor-faktor yang mempertimbangkan potensi biofisik berupa data jumlah harian hujan pertahun, jumlah harian penyinaran matahari, diversitas fauna berupa aves.

\section{Analisis Data}

Data lapangan dihitung menggunakan rumus interval kelas potensi.

a. Menentukan interval kelas potensi

$$
\begin{aligned}
& \text { Varians }\left(\mathrm{S}^{2}\right)=\frac{\sum(\mathrm{X}-\mathrm{X})^{2}}{\mathrm{n}-1} \\
& \text { Standar deviasi }(\mathrm{Sd})=\sqrt{\frac{\sum(\mathrm{X}-\overline{\mathrm{X}})^{2}}{\mathrm{n}-1}}
\end{aligned}
$$

b. Menentukan kelas potensi

$$
\begin{aligned}
& \text { Tinggi }:>\bar{X}+\frac{S d}{2} \text {. } \\
& \text { Sedang }:\left(\overline{\mathrm{X}}-\frac{S d}{2)}-\left(\overline{\mathrm{X}}+\frac{S d}{2}\right)\right. \text {. } \\
& \text { Rendah }:<\overline{\mathrm{X}}-\frac{S d}{2} \text {. }
\end{aligned}
$$

\section{Analisis SWOT}

Metode analisis Strength, Weakness, Opportunity dan Threath (SWOT) dilakukan untuk mengetahui permasalahan pengembangan LMC secara deskriptif kualitatif. Potensi LMC dikaji dengan menilai komponen-komponen terkait dan dikelompokkan menjadi faktor strength atau potensi, weakness atau kendala/kelemahan, opportunity atau peluang dan threath atau tantangan. Dengan mengkaji secara menyeluruh ke empat faktor tersebut dapat diketahui arah pengembangan.

\section{HASIL DAN PEMBAHASAN}

\section{Potensi Objek Daya Tarik Wisata (ODTW) LMC} Lampung Manggove Center (LMC) merupakan salah satu kawasan hutan manggroveyang memiliki nilai sejarah, keindahan vegetasi serta satwa yang jika dikembangkan menjadi tujuan ekowisata dapat menambah pendapatan masyarakat. Hasil pengamatan lapangan diketahui potensi ODTW LMC disajikan pada Tabel 2 berikut ini. 
Tabel 1. Penentuan Kelas Potensi Objek Wisata LMC

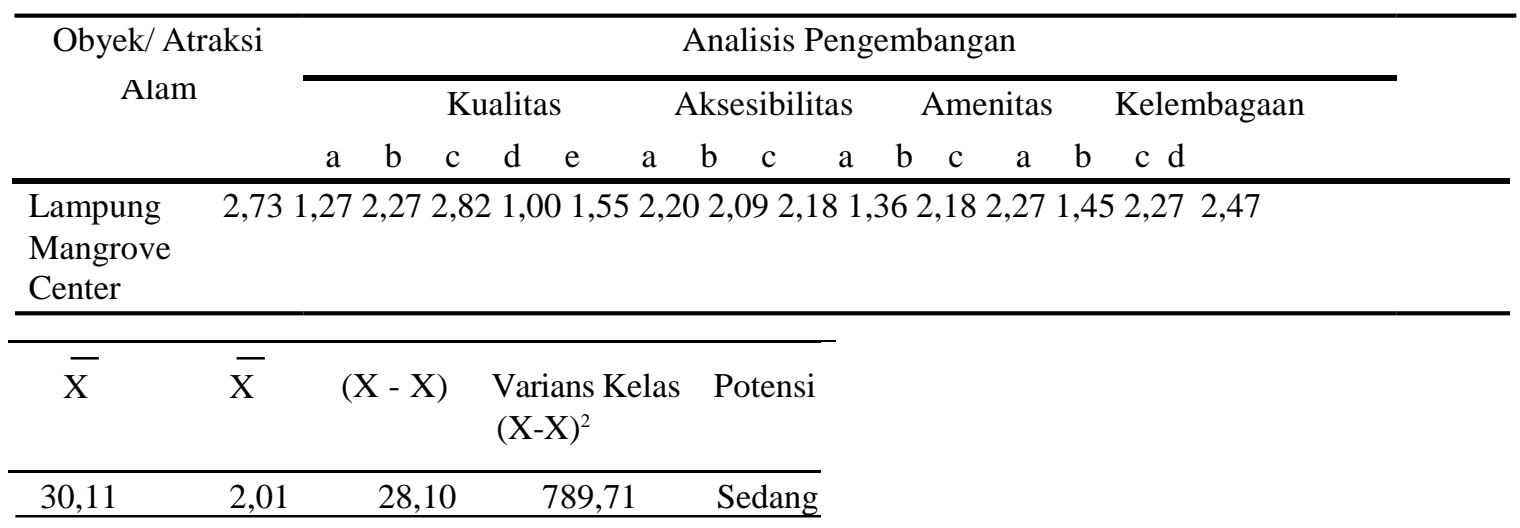

Berdasarkan Tabel 1, potensi LMC masih sangat alami dan belum termodifikasi bentang alamnya. Hal ini perlu dipertahankan karena, semakin alami suatu obyek maka semakin menarik obyek tersebut (Skor 2,68). Keunikan diartikan sebagai kombinasi kelangkaan dan daya tarik yang khas melekat pada suatu obyek wisata. LMC dalam hal ini belum dikatakan unik karena baik di dalam maupun diluar Kabupaten Lampung Timu masih banyak kawasan hutan mangrove yang sama (Skor 1,18). Keindahan mencerminkan kepuasan dalam menikmati suatu obyek dan didukung panorama alam sekitarnya. Dari hasil pengamatan di lapangan, panorama di LMC sangat indah. Perpaduan gradasi warna hamparan mangrove, panorama alam serta aktifitas burung disekitar hutan mangrove menjadikan kawasan ini sangat indah untukdinikmati.Pengalaman menyusuri hutan mangrove akan menjadi sangat mengesankan. (Skor 2,27). Keutuhan diartikan sebagai kesatuan unsur- unsur fisik dalam mendukung daya tarik suatu obyek. Keterpaduan unsur - unsur fisik dalam kawasan tampak membentuk ekosistem yang khas (Skor 2,82). Ketersediaan lahan pengembangan diartikan sebagai areal yang dapat dipergunakan wisatawan dalam berwisata. Areal yang baik dapat memberikan rasa nyaman bagi setiap wisatawan dalam melakukan aktivitasnya. Di lokasi penelitian areal yang tersedia sangat luas sehingga mampu menampung hampir 100 orang perkunjungan, (Skor 1).

Aksesibilitas diartikan sebagai infrastruktur dan modal transportasi yang merupakan kunci keberhasilan pengembangan suatu obyek wisata. Untuk mencapai kawasan LMC telah tersedia angkutan umum dari ibukota povinsi maupun dari ibu kota kabupaten (Skor 2,20). Amenitas adalah infrastruktur yang sebenarnya tidak langsung terkait dengan pariwisata tetapi sering menjadi bagian dari kebutuhan wisatawan. Namun untuk fasilitas pendukung seperti shelter dan WC umum, papan interpretasi, papan petunjuk arah, pusat informasi, souvenir shop, restoran/warung makan, pintu gerbang belum tesedia di setiap titik pengamatan atau titik jalur wisata (Skor 2,18). Kelembagaan pariwisata sangat kompleks karena diperlukan perencanaan yang matang serta kolaboratif dengan berbagai pihak untuk menjaga kelestarian ODTW tersebut. Selain itu, sebagai suatu produk wisata yang berbentuk jasa (pelayanan) suatu destinasi harus dikemas sedemikian rupa agar dapat menarik wisatawan. Saat ini, ODTW LMC dikelola oleh yang kelompok masyarakat pelestari mangrove di bawah konsosium Unila dan Lampung Timur. Berdasarkan pengamatan di lapangan, hanya sekitar 5 orang yang biasa melayani wisatawan sebagai guide, (Skor.1,45).

\section{Potensi Flora dan Fauna}

Jenis mangrove di pesisir Lampung Timur yaitu Avicennia marina, Avicennia officinalis, Rhizophora apiculata, Aegiceras, Xylocarpus, spp., Rhizophora stylosa, Sonneratia caseolans, Cerbera maghas, Rhizophora mucronata, dan Bruguiera gymnorhiza, (Roehana, 2011)

Potensi satwa liar teresterial yang hidup di hutan mangrove Kecamatan Labuhan Maringgai, yaitu mamalia, aves dan reptilia. Kelas Mamalia terdiri dari 2 jenis, 19 jenis aves, dan 7 jenis reptilia (Hastuti, 2003). Kesuma, dkk, (2013) menyebutkan spesies burung yang ditemukan di Desa Margasari 
terdiri dari 20 spesies, 995 individu dari 13 famili. Keanekaragaman jenis tergolong kriteria sedang, dengan nilai 2,109. Hutan mangrove yangberbatasan dengan sawah memiliki nilai 2,388 dan yang berbatasan dengan tambak memiliki nilai 2,188.
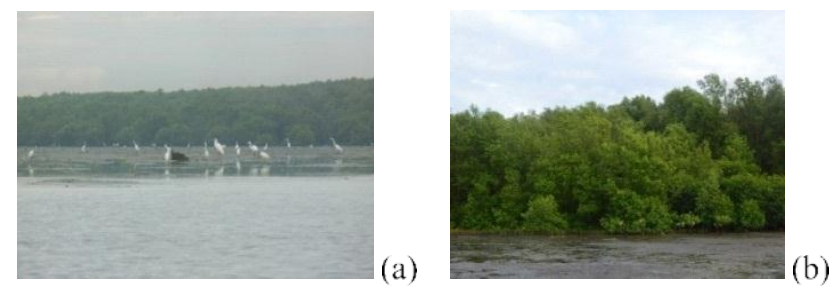

Gambar 1. (a) Burung Kuntul (b) Mangrove jenis api-api

Persepsi dan Preferensi Masyarakat dan Wisatawan Terhadap Pengembangan Ekowisata Bebasis Masyarakat di LMC

Ekowisata berbasis masyarakat sangat menekankan ketelibatan penuh masyarakat dalam pengelolaan wisata. Persepsi masyarakat terhadap kawasan dan pengembangan ekowisata sangat penting untuk diketahui karena secara langsung berhubungan dengan kegiatan yang ada pada kawasan tersebut dan yang terpenting adalah menumbuhkan rasa memiliki (sense of belonging) terhadap LMC sehingga pengelolaannya dapat berlangsung secara lestari dan optimal serta meningkatnya kesejahteraan masyarakat.

\section{Kondisi Sosial Ekonomi Masyarakat Desa Magasari}

Berdasarkan data yang diperoleh, berikut keadaan sosial ekonomi masyarkat Desa Margasari yang terdiri dari bermacam-macam suku dan adat istiadat.

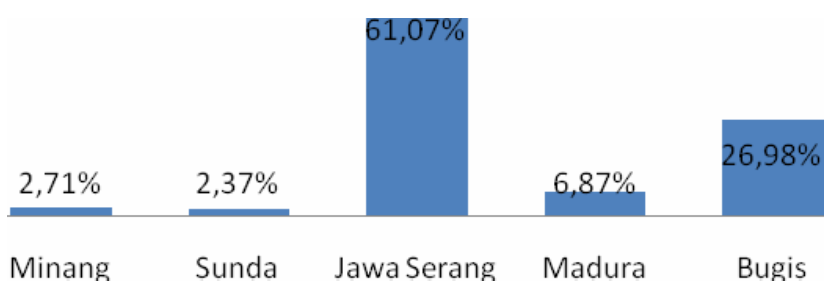

Gambar 2. Jumlah Penduduk berdasarkan Suku

di Desa Margasari.

Sumber: Monografi Kelurahan Desa Margasari Kecamatan Labuhan Maringgai Kabupaten Lampung Timur (2012).

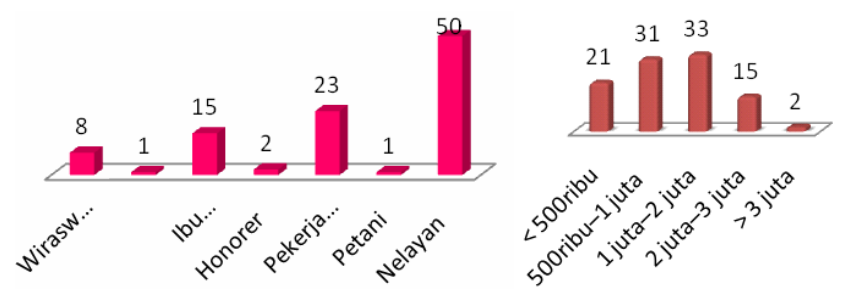

Gambar 3. Profil Responden Berdasarkan Mata Pencaharian dan Penghasilan tiap Bulan di Desa Margasari.

\section{Tanggapan Terhadap Pengembangan Ekowisata Bebasis Masyarakat di LMC}

Hasil wawancara dengan responden, sebanyak 98 orang (98\%) mendukung adanya kegiatan pengembangan ekowisata di LMC dan sekitar 2 orang (2\%) yang menyatakan tidak setuju. Masyarakat menyatakan siap untuk berpatisipasi asalkan tidak mengganggu mata pencaharian mereka yang kebanyakan adalah nelayan dan petani.

Tabel 2. Persepsi Masyarakat Terhadap Objek Wisata LMC

\begin{tabular}{|c|c|}
\hline Persepsi Masyarakat & Jumlah (\%) \\
\hline $\begin{array}{l}\text { Pengetahuan masyarakat tentang arti } \\
\text { hutan mangrove }\end{array}$ & 31 \\
\hline $\begin{array}{l}\text { Pengetahuan masyarakat tentang hutan } \\
\text { mangrove sebagai objek wisata }\end{array}$ & 51 \\
\hline $\begin{array}{l}\text { Pengetahuan masyarakat tentang } \\
\text { manfaat dari objek wisata alam bagi } \\
\text { perekonomian masyarakat }\end{array}$ & 100 \\
\hline $\begin{array}{l}\text { Pengetahuan masyarakat tentang pe- } \\
\text { nebangan hutan mangrove secara liar } \\
\text { merusak lingkungan }\end{array}$ & 100 \\
\hline $\begin{array}{l}\text { Pengetahuan masyarakat tentang peng- } \\
\text { embangan objek wisata di LMC }\end{array}$ & 98 \\
\hline
\end{tabular}

Keterlibatan masyarakat dalam rangka pengembangan ekowisata di LMC dapat dilihat pada Gambar 4. Keinginan masyarakat untuk berpartisipasi dalam kegiatan pengembangan ekowisata LMC berupa wirausaha / jualan, jasa sewa kapal, jasa penginapan, jasa tour guide, belum berminat. Partisipasi masyarakat terhadap wirausaha/ jualan relatif tinggi, yaitu $56 \%$ karena Sumber Daya Manusia (SDM) yang dimiliki masyarakat tidak memumpuni untuk menjadi tour guide. 
Masyarakat yang ingin berpartisipasi dalam tour guide biasanya orang yang memiliki tingkat pendidikan SMA hingga sarjana atau yang sudah terbiasa melakukan kegiatan dengan wisatawan.

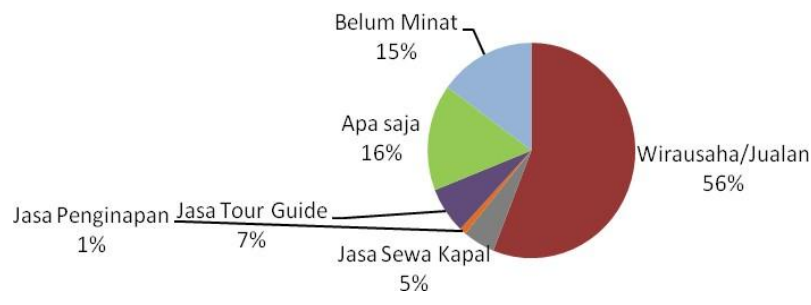

Gambar 4. Minat Masyarakat untuk Berpartisipasi dalam Pengembangan Ekowisata di LMC

\section{Persepsi Wisatawan untuk Pengembangan Eko- wisata Berbasis Masyarakat di LMC}

Hasil pengkajian terhadap motivasipengunjung menunjukkan bahwa minat pengunjung untuk menikmati keindahan panorama hutan mangrove di LMC, penelitian di hutan mangrove dan menyusuri hutan mangrove (tracking).

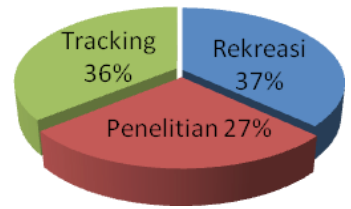

Gambar 5. Motivasi dan Minat Wisatawan Berkunjung ke LMC.

\section{Daya Dukung}

Keindahan greenbelt mangrove di LMC dapat dijadikan pengembangan objek daya tarik wisata minat khusus berbasis masyarakat. LMC memiliki daya tarik untuk dikunjungi oleh wisatawan yang membutuhkan pendidikan, hal ini merupakan sesuatu yang menarik untuk dapat dilakukan bagi wisatawan (something to do). Selain itu, LMC juga dapat menjadi daya tarik wisata yang menarik untuk dapat melihat keindahan hutan manggrove, keanekaragaman burung serta fauna lainnya bagi wisatawan (something to see). Berdasarkan hasil wawancara, jumlah kunjungan pada waktu tertentu seperti liburan tahun baru dan liburan hari, bisa sangat banyak dan memenuhi LMC namun keramaian hanya pada kawasan pinggir pantai tapatnya di tanggul batu, oleh karena itu pembatasan jumlah kunjungan perlu diterapkan pada kawasan LMCuntuk tetap menjaga keamanan serta kenyamanan wisatawan yang berkunjung utamanya pada waktu-waktu yang berpotensi terjadi lonjakan jumlah pengunjung.

Carrying Capacity secara implisit berarti batasan (limit), batas atas (ceiling), dan tingkatan/ level (threshold) yang tidak boleh dilewati dalam pembangunan dan pengembangan destinasi pariwisata serta memiliki faktor pengaruh yaitu karakteristik wisatawan, daya tampung kawasan dan atribut destinasi dan zonasi Kawasan. Daya Tampung adalah kemampuan suatu lingkungan binaan seperti kawasan perumahan, kawasan industri, perkotaan banyak diperhitungan dengan kosep daya dukung (Fandeli, 2009).

Tabel 3. Daya Dukung Ekowisata LMC.

\begin{tabular}{cccc}
\hline \multirow{2}{*}{ Objek } & \multicolumn{3}{c}{ Daya Dukung (Carrying Capacity) } \\
\cline { 2 - 4 } Wisata & Daya Dukung & Daya Dukung & Daya Dukung Rii \\
LMC & Ekologis (Ha) & Fisik & (Orang/hari) \\
& & (Kungjungan/hari) & \\
\hline PlotMangove & 0,012 & 979 & 170 \\
\hline
\end{tabular}

Daya dukung ekowisata LMC menggunakan pendekatan ekologis, fisik dan riil. Apabila dilihat pada daya dukung ekologis, kemampuan suatu areal dalam menampung wisata 0,012 ha sedangkan pada daya dukung fisik dapat menampung 979 kunjungan per hari. Kemampuan objek wisata dalam menampung orang per hari minimal 170 orang per hari. Hal ini berdasarkan faktor koreksi (Cf), hanya menggunakan penyinaran matahari, hujan dan indeks keanekaragaman burung oleh Shanon Winner serta hasil penelitian Kesuma, dkk pada tahun 2013 mengenai keanekaragaman burung di LMC. Adapun fasilitas yang menunjang ekowisata di LMC serta daya dukung fasilitas, yaitu.

Tabel 4. Daya Dukung Fasilitas Ekowisata di LMC

\begin{tabular}{|c|c|c|c|}
\hline Fasilitas & & Jumlah & $\begin{array}{c}\text { Daya Tampung } \\
\text { (Kapasitas } \\
\text { Orang) }\end{array}$ \\
\hline Perahu & $\begin{array}{l}\text { a. } \\
\text { b. }\end{array}$ & $\begin{array}{l}\text { Besar }=2 \\
\text { Kecil }=6\end{array}$ & $\begin{array}{l}\text { a. } 6 \text { orang } \\
\text { b. } 4 \text { orang }\end{array}$ \\
\hline Menara birdwatching & & 1 & 24 orang \\
\hline Rumah Baca & & 1 & 90 orang \\
\hline Saung Rumah Baca & & 1 & 50 orang \\
\hline
\end{tabular}

Sumber: Data Primer (2016). 

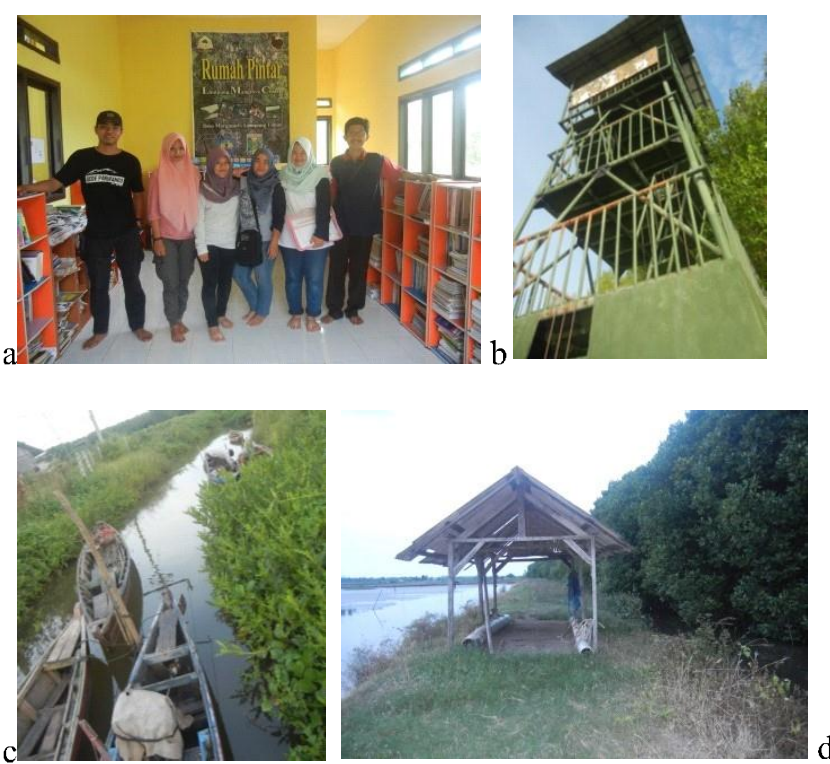

Gambar 6. (a) Rumah baca LMC, (b) Menara Birdwatching, (c) Penyewaan prahu, dan (d) Plot Manggrove

\section{Pengembangan Ekowisata Bebasis Masyarakat di LMC}

Seluruh aspek dikelompokkan menjadi kelompok internal dan eksternal. Kelompok internal Strenght dan Weakness dan kelompok eksternal yakni Opportunity dan Threat. Adapun hasil analisis SWOT untuk kawasan LMC diuraikan dalam Gambar 7.

\section{KESIMPULAN}

Kesimpulan dalam penelitian bahwa potensi hutan mangrove di LMC tergolong kategori sedang, sebanyak $98 \%$ persepsi masyarakat menyatakan setuju jika dikembangkan untuk ekowisata berbasis masyarakat. Motivasi wisatawan yang berkunjung sebanyak $27 \%$ untuk penelitian, 37 $\%$ untuk rekreasi. Daya dukung riil kawasan LMC dapat menampung sebanyak 170 orang/hari, dan

\begin{tabular}{l} 
KEKUATAN (STRENGHT) \\
\hline 1) Keunikan kawasan yang terdiri dari hampaan vegetasi \\
mangove dan satwa buung . \\
2) Kualitas atraksi sedang dengan nilai ... \\
3) Panorama alam yang indah dan masih alami pada saat \\
menyusui sungai di antaa tegakan mangove. \\
4) Aksisibilitas tinggi. \\
5) Kehidupan sosial budaya masyarakat yang ramah tamah. \\
6) Tanggapan masyarakat setempat yang positif \\
7) Keinginan masyarakat untuk ikut berpartisifasi aktif. \\
8) Dukungan dari pemda setempat dan stakeholders \\
9) Dukungan dari aparat Desa.
\end{tabular}

KELEMAHAN(WEAKNNES)

1) Fasilitas pendukung kurang mencukupi

2) Kualitas atraksi alam sedang

3) Struktur organisasi dan manajemen yang ada kurang mendukung

4) Koordinasi antara pengelola dengan sesama stekeholders belum.

5) Kurangnya informasi, pemasaran dan promosi.

9) Adanya kon $\square \mathrm{ik}$ intenal.

Skenario pengembangan I

1) Mitra lokal potensial banyak tersedia

2) Kelembagaan kelompok masyarakat tersedia yaitu dengan mendorong atau meningkatkan seluruh kekuatan yang dimiliki serta mengoptimalkan SDM dan kinerja untuk meraih seluruh peluang yang ada.
3) Persepsi dan apresiasi menciptakan iklim yang kondusif .

4) Dengan ekowisata bebasis masyaakat memberi peluang untuk memperoleh kesempatan kerja dan berusaha sehingga akan meningkat kesajahteraannya.
Skenario pengembangan III yaitu dengan mendorong atau meningkatkan seluruh kekuatan yang dimiliki untuk meminimalisir ancaman-ancaman yang mungkin timbul.
Skenario pengembangan II yaitu dengan memperbaiki kelemahan-kelemahan yang ada untuk meraih seluruh peluang ada.

Skenario Pengembangan IV yaitu dengan memperbaiki kelemahan-kelemahan yang ada untuk meminimalisir ancamanancaman yang mungkin timbul

2) Dimungkinkan adanya perubahan kultur masyarakat sebagai akibat dari persentuhan budaya.

3) Dimungkinkan adanya pesaingan usaha

Gambar 7. Analisis SWOT Kawasan LMC 
daya dukung fasilitas dan amenitas 174 orang/ kunjungan. Analisis SWOT menggambarkan hutan mangrove di LMC berpotensi untuk dikembangkan sebagai tujuan ekowisata berbasis masyarakat. Adapun saran yang dapat diberikan yaitu perlunya penambahan fasilitas dan amenitas serta penelitian lanjutan mengenai strategi pengembangan hutan manggrove di LMC sebagai destinasi ekowisata berbasis masyarakat.

\section{DAFTAR PUSTAKA}

Fandeli, Ch. 2002. Perencanaan Kepariwisataan Alam. Fakultas Kehutanan Universitas Gajah Mada, Yogyakarta.

Fandeli, C dan Muhammad. 2009. Prinsip- Prinsip Dasar Mengkonservasi Lanskap. Yogyakarta: GajahMada University Press.

Hastuti, Y. D., 2003. Struktur, komposisi dan keberadaan satwa liar teresterial di areal rehabilitasi hutan mangrove Desa Margasari dan Desa Sriminosari Kecamatan Labuhan Maringgai Kabupaten Lampung Timur. Skripsi. Universitas Lampung. Bandar Lampung.

Kesuma, M. I., Dewi, B. S. dan Nurcahyani, N., 2013. Keanekaragaman jenis burung di Lampung Mangrove Center Desa Margasari Kecamatan Labuhan Maringgai Kabupaten Lampung Timur. Prosiding Seminar Nasional
Sains dan Teknologi V. Lembaga Penelitian Universitas Lampung. 19-20 November 2013.

Kustanti, A. 2007. Manajemen Hutan Mangrove. Monografi Desa Margasari. 2012. Potensi Desa, Kecamatan Labuhan Maringgai, Kabupaten Lampung Timur, Provinsi Lampung. Buku Teks. 236 hal.

Monografi Desa Margasari. 2012. Potensi Desa, Kecamatan Labuhan Maringgai, Kabupaten Lampung Timur, Provinsi Lampung. Lampung. Rochana, Erna. 2011. Ekowisata Mangrove Pesisir Lampung Timur. Lampung: Lembaga Penelitian Universitas Lampung.

Wirendo, S. et all. 2009. Potret Keadaan Hutan Indonesia Periode 2000-2009. Forest Watch Indonesia 